Supporting Information

\title{
Preparation of antibacterial softwood via chemical attachment of quaternary ammonium compounds using supercritical $\mathrm{CO}_{2}$
}

\author{
William Z. Xu, Lijuan Yang, and Paul A. Charpentier* \\ Department of Chemical and Biochemical Engineering, University of Western Ontario, \\ 1151 Richmond Street, London, ON, Canada N6A 5B9
}

32 Pages and 31 Figures in total. 


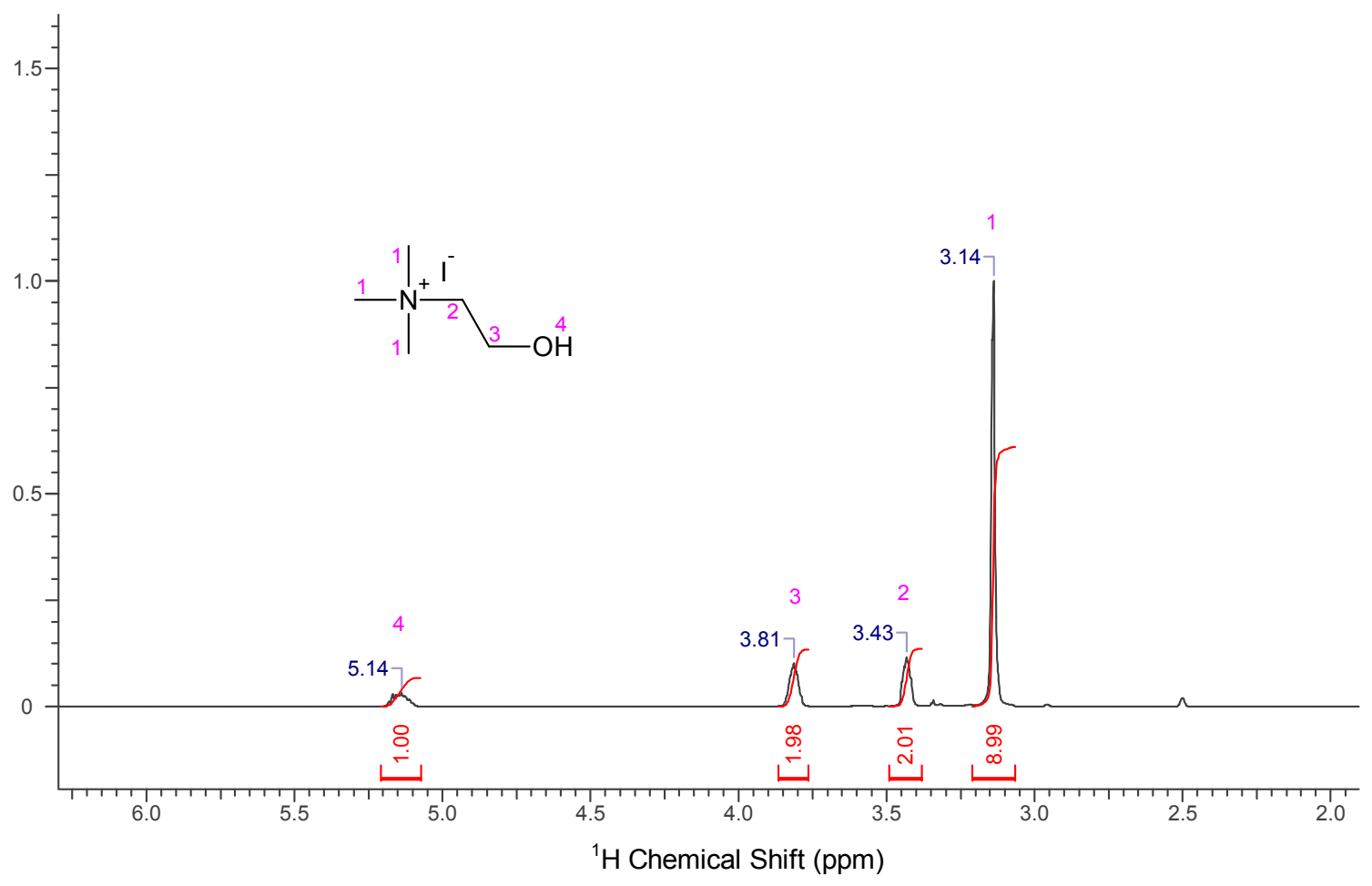

Fig $\mathbf{S} 1{ }^{1} \mathrm{H}$ NMR spectrum of TMEAI (1) in DMSO_d $\mathrm{d}_{6}$ 


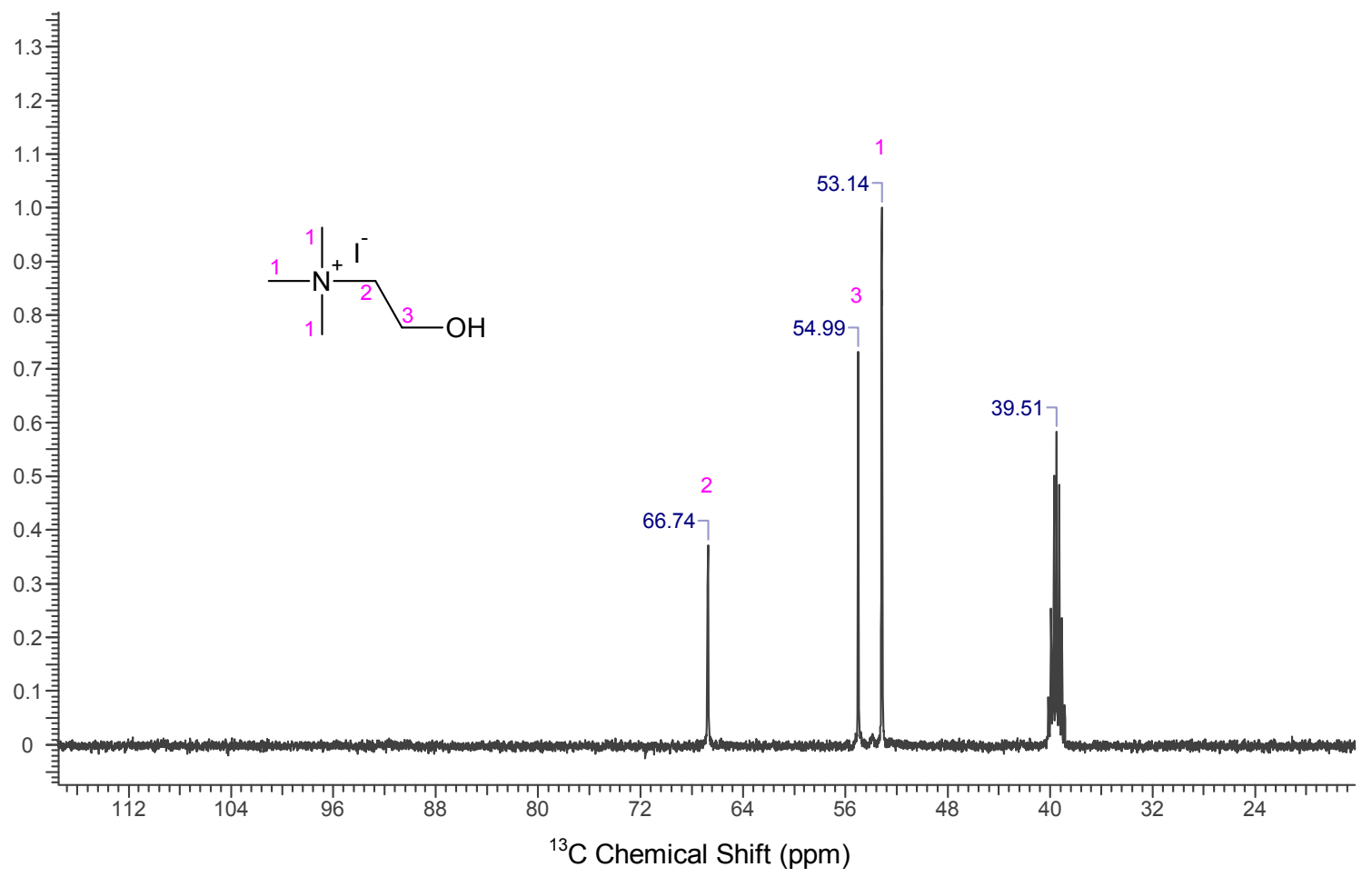

Fig S2 ${ }^{13} \mathrm{C}$ NMR spectrum of TMEAI (1) in DMSO_d $d_{6}$. 


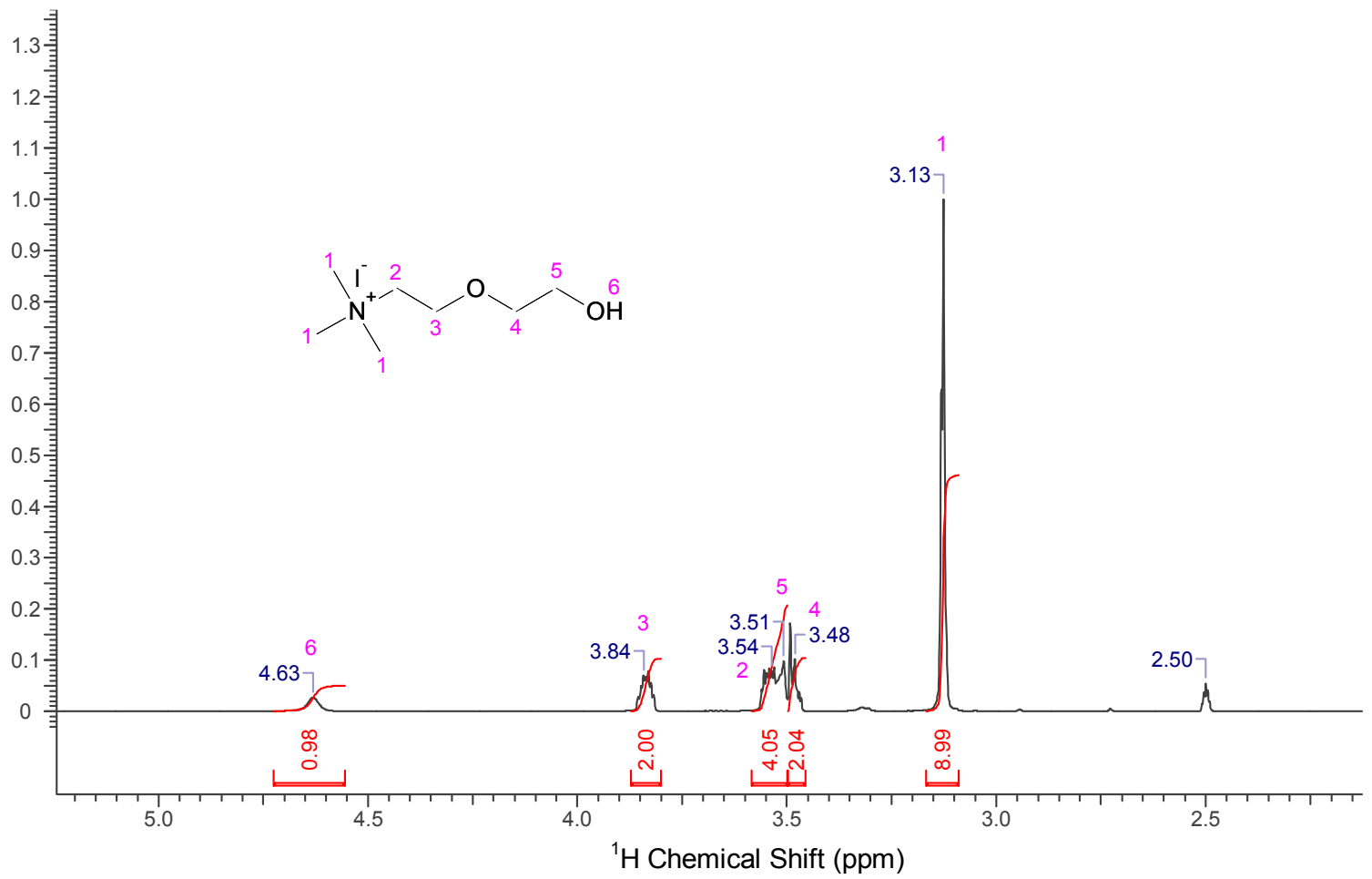

Fig S3 ${ }^{1} \mathrm{H}$ NMR spectrum of TMEEAI (2) in DMSO_d $\mathrm{d}_{6}$. 


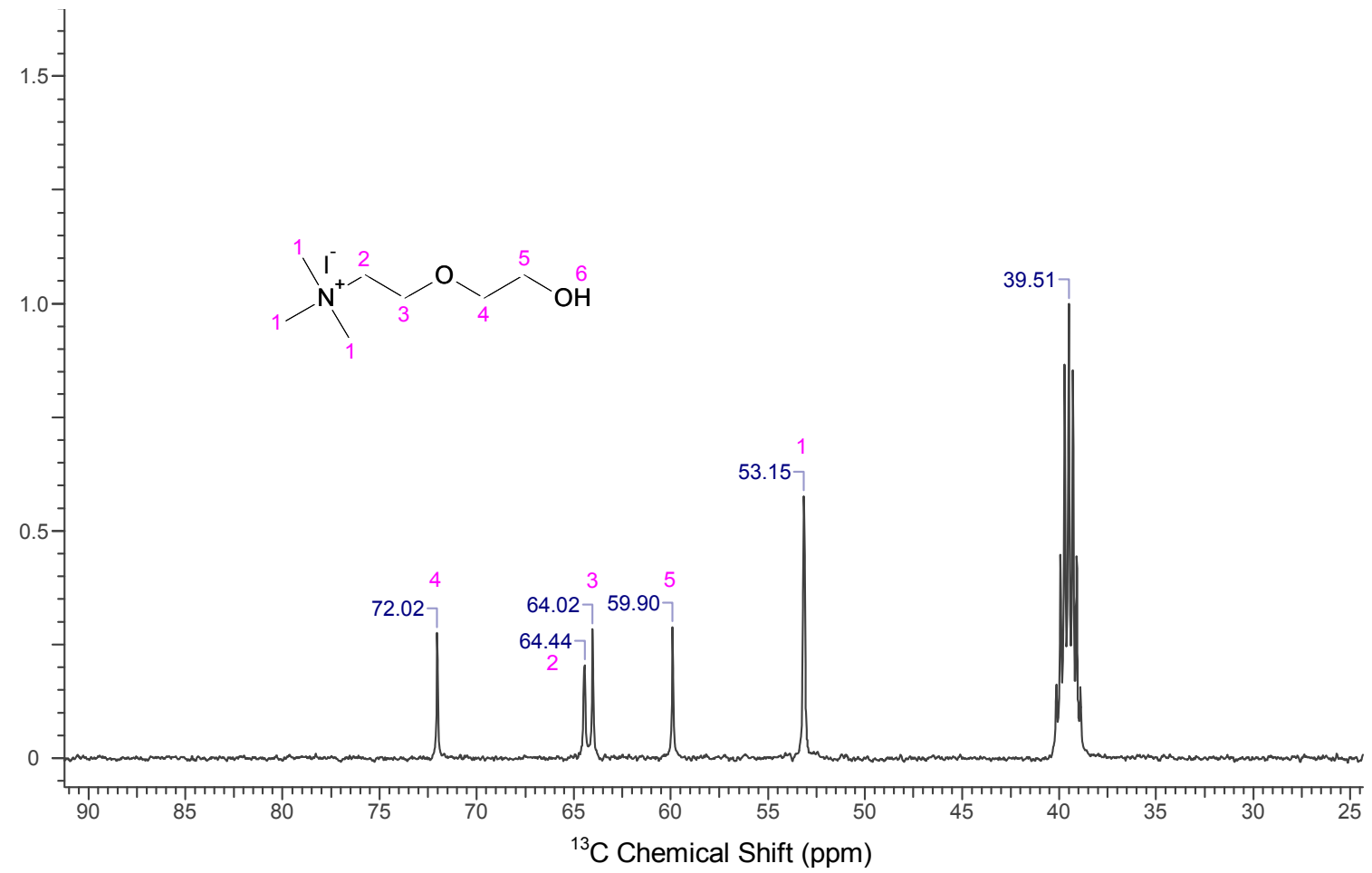

Fig $54{ }^{13} \mathrm{C}$ NMR spectrum of TMEEAI (2) in DMSO_d $\mathrm{d}_{6}$. 




Fig S5 gHSQC NMR spectrum of TMEEAI (2) in DMSO_d $d_{6}$. 


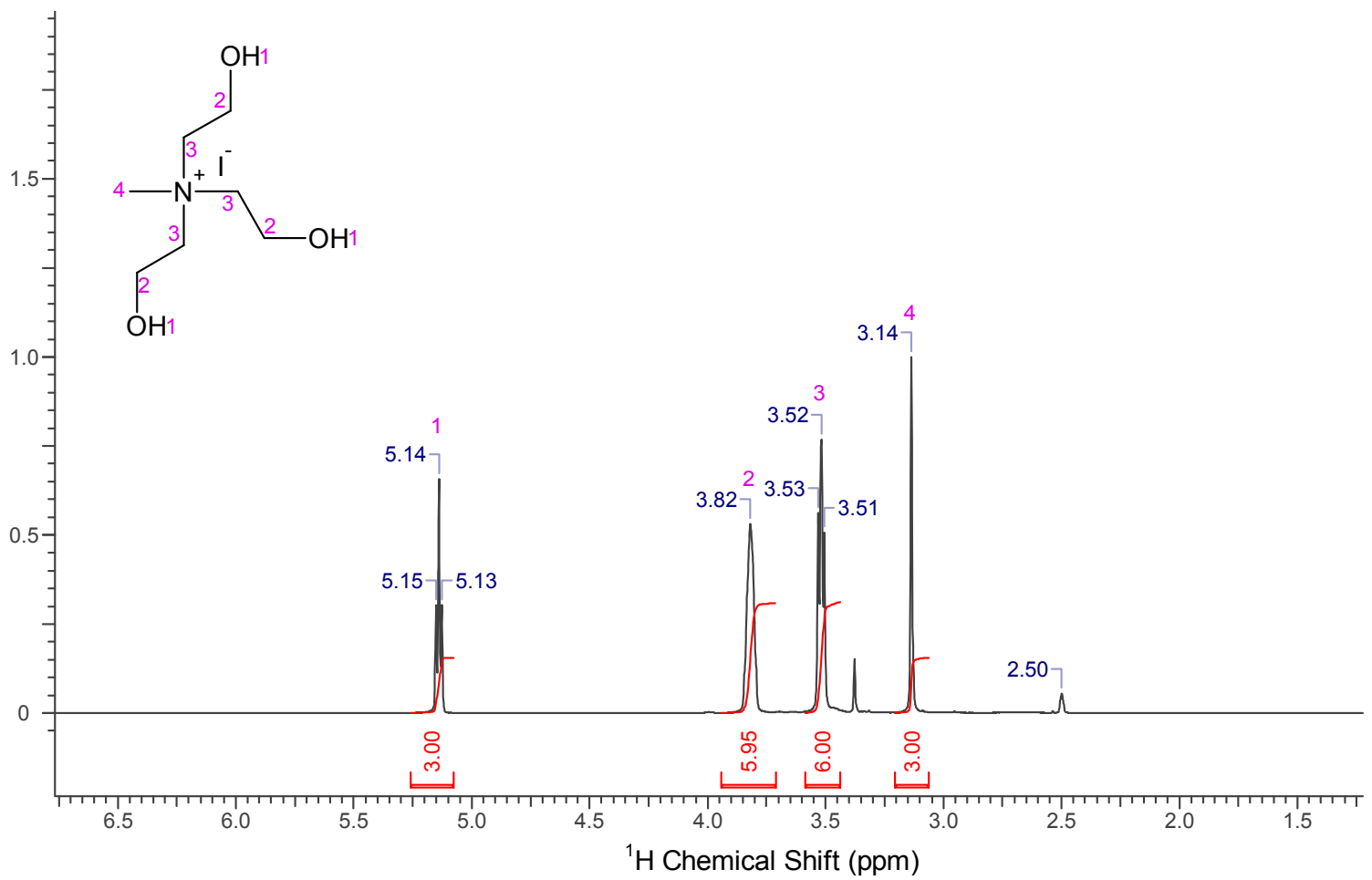

Fig S6 ${ }^{1} \mathrm{H}$ NMR spectrum of MTEAI (3) in DMSO_d $\mathrm{d}_{6}$. 


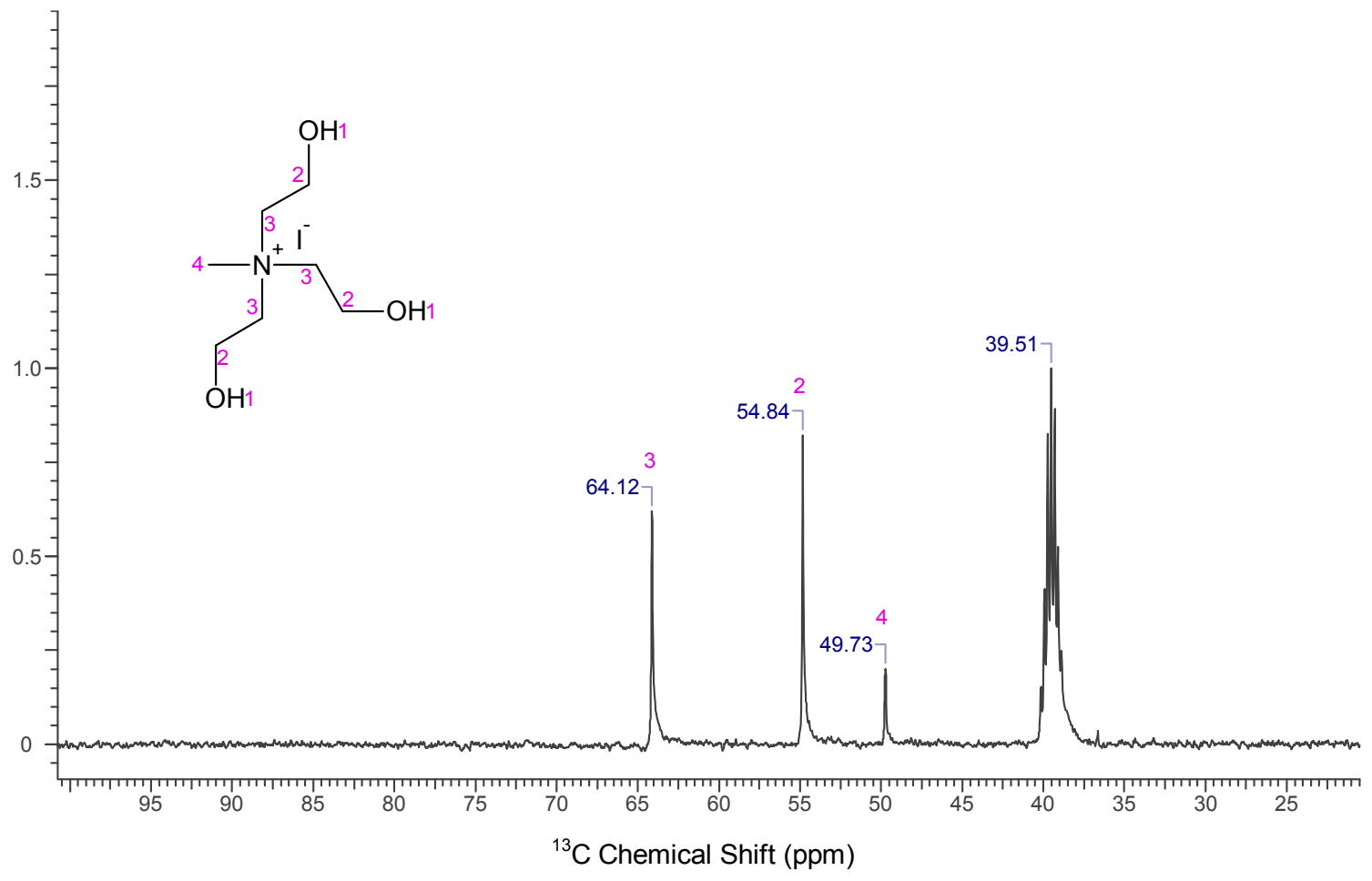

Fig $57{ }^{13} \mathrm{C}$ NMR spectrum of MTEAI (3) in DMSO_d $\mathrm{d}_{6}$. 


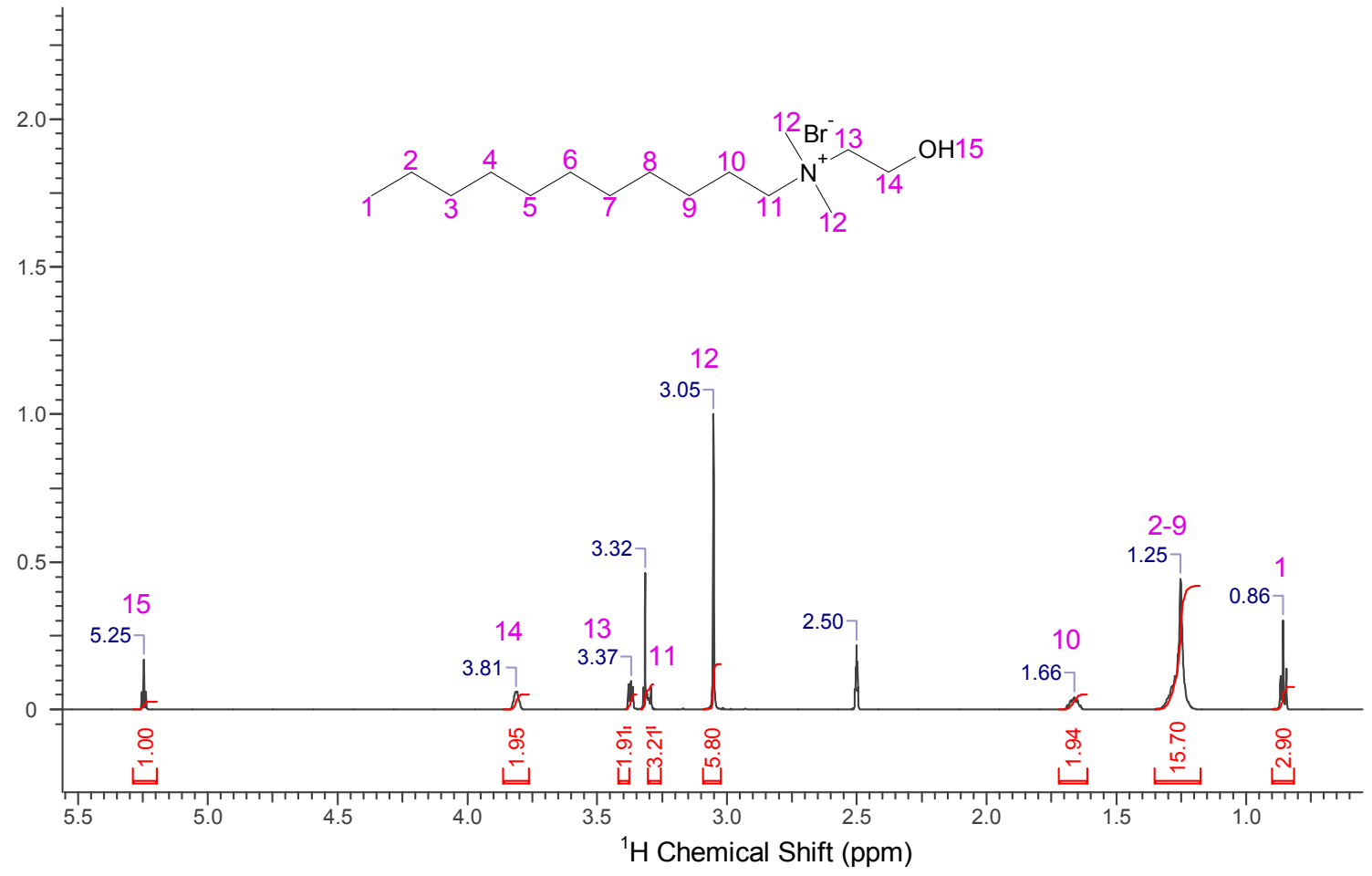

Fig S8 ${ }^{1} \mathrm{H}$ NMR spectrum of HEdMUABr (4) in DMSO_ $d_{6}$. 


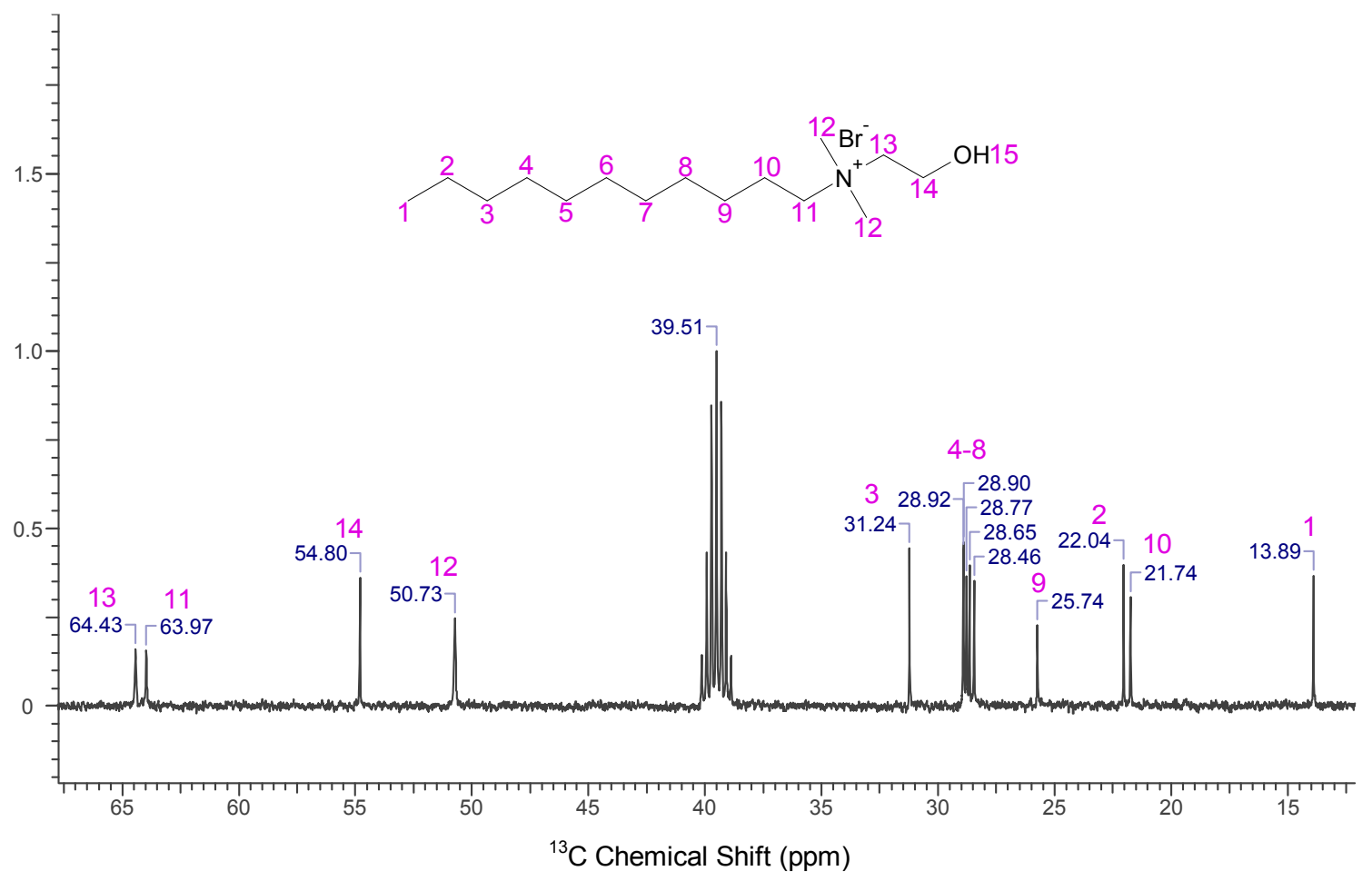

Fig $59{ }^{13}$ C NMR spectrum of HEdMUABr (4) in DMSO_d $d_{6}$. 


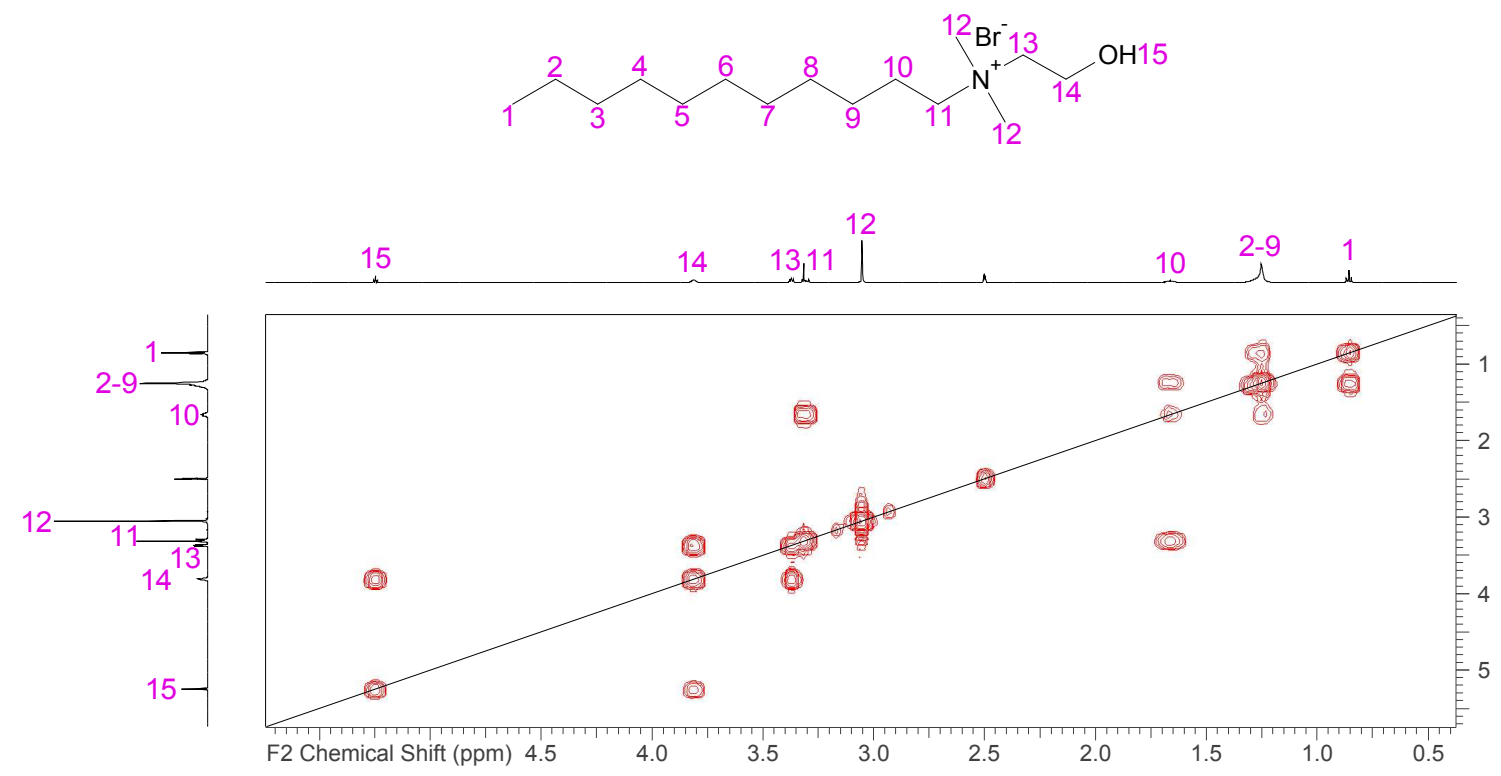

Fig S10 gCOSY NMR spectrum of HEdMUABr (4) in DMSO_d $d_{6}$. 


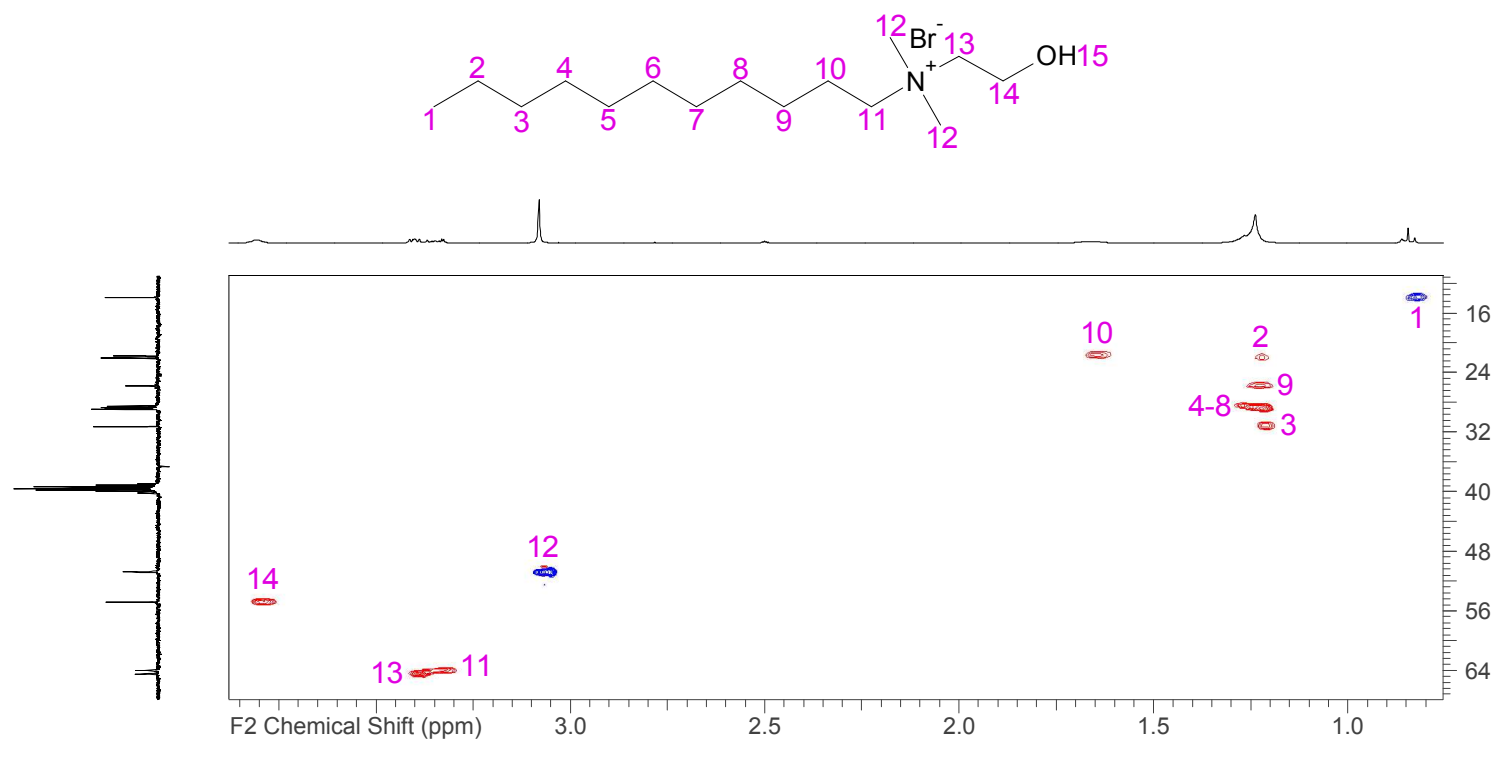

Fig S11 gHSQCAD NMR spectrum of HEdMUABr (4) in DMSO_d $d_{6}$. 


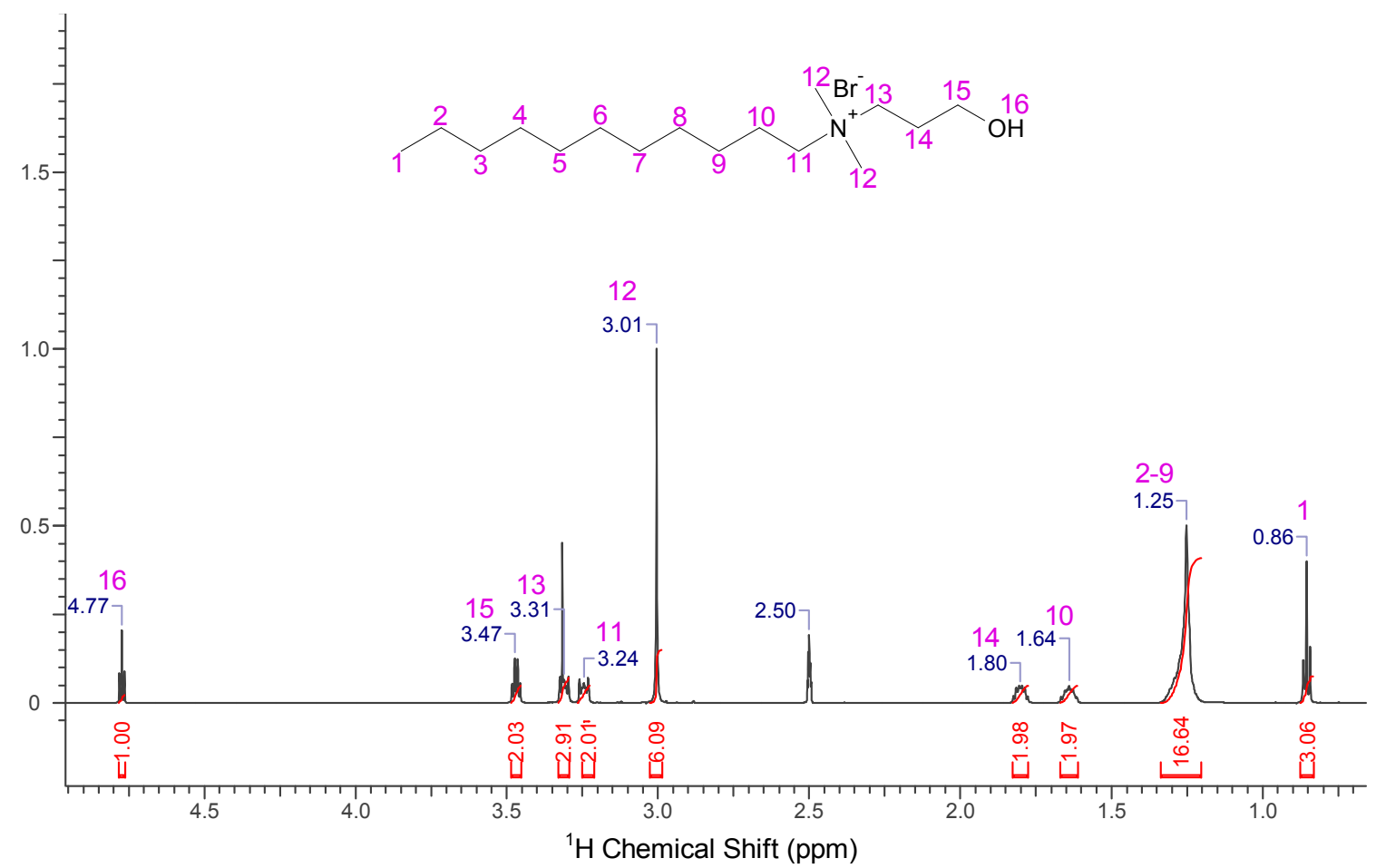

Fig S12 ${ }^{1} \mathrm{H}$ NMR spectrum of HPdMUABr (5) in DMSO_ $d_{6}$. 


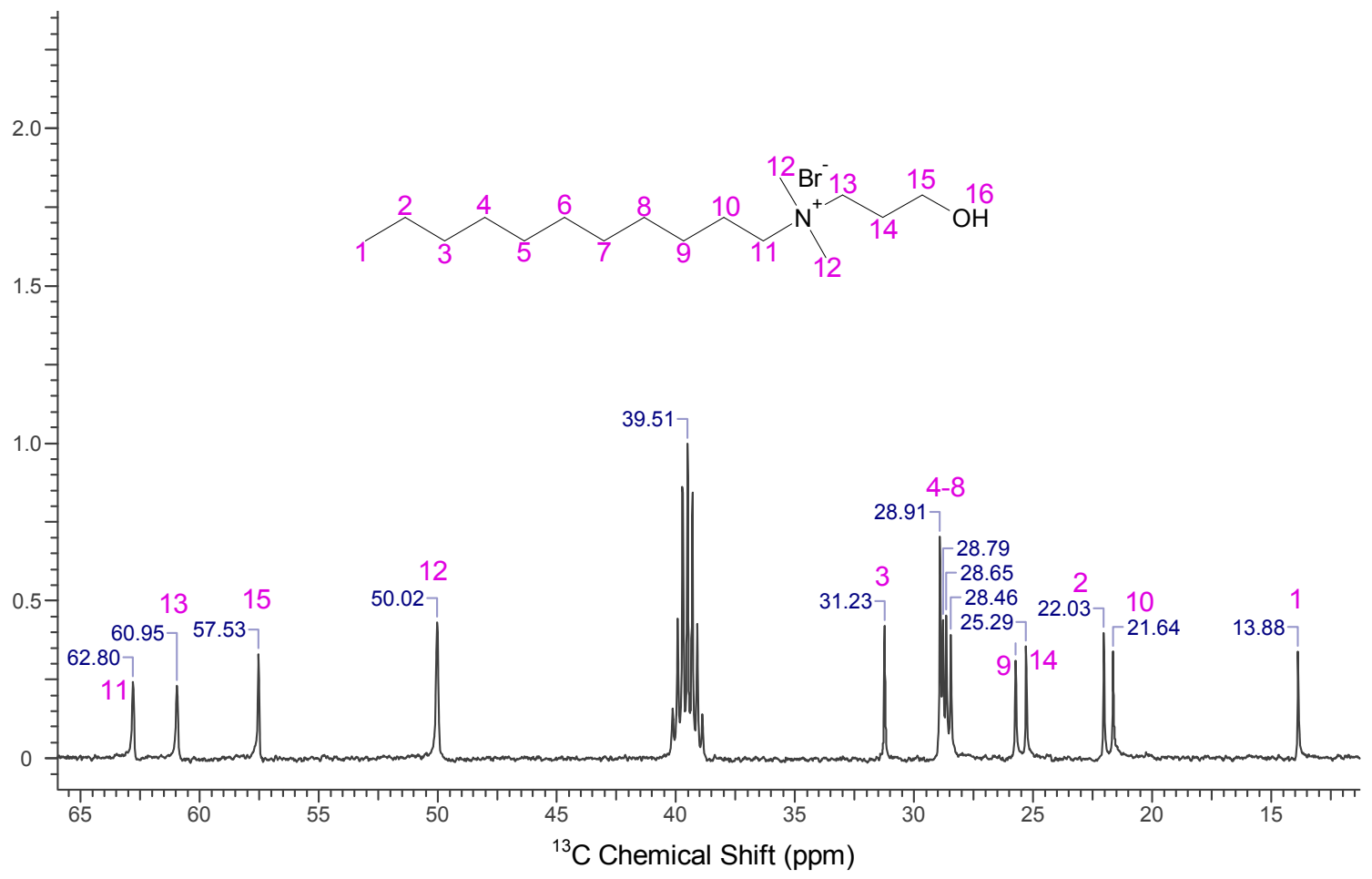

Fig $S 13{ }^{13}$ C NMR spectrum of HPdMUABr (5) in DMSO_d $d_{6}$. 


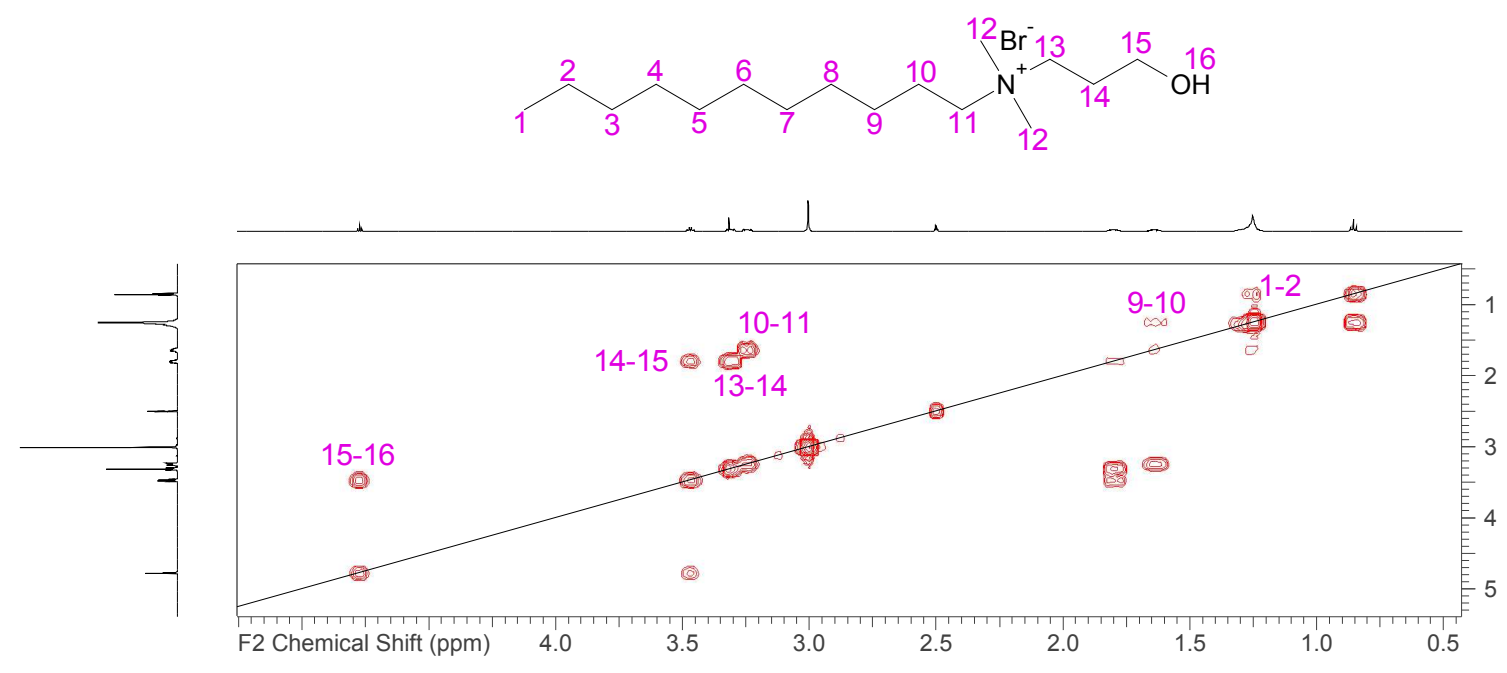

Fig S14 gCOSY NMR spectrum of HPdMUABr (5) in DMSO_d $\mathrm{d}_{6}$. 


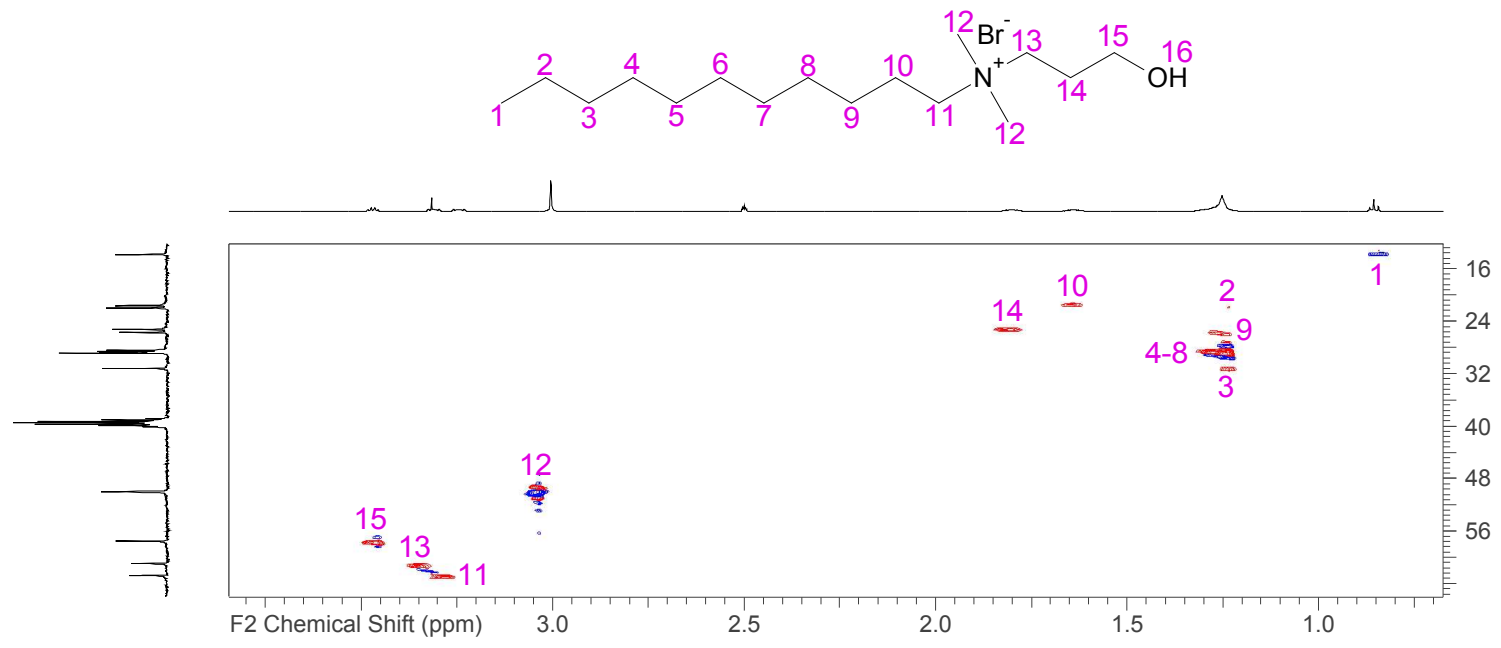

Fig S15 gHSQCAD NMR spectrum of HPdMUABr (5) in DMSO_d 6 . 




Fig S16 ${ }^{1} \mathrm{H}$ NMR spectrum of HHPdMUABr (6) in DMSO_d $\mathrm{d}_{6}$. 


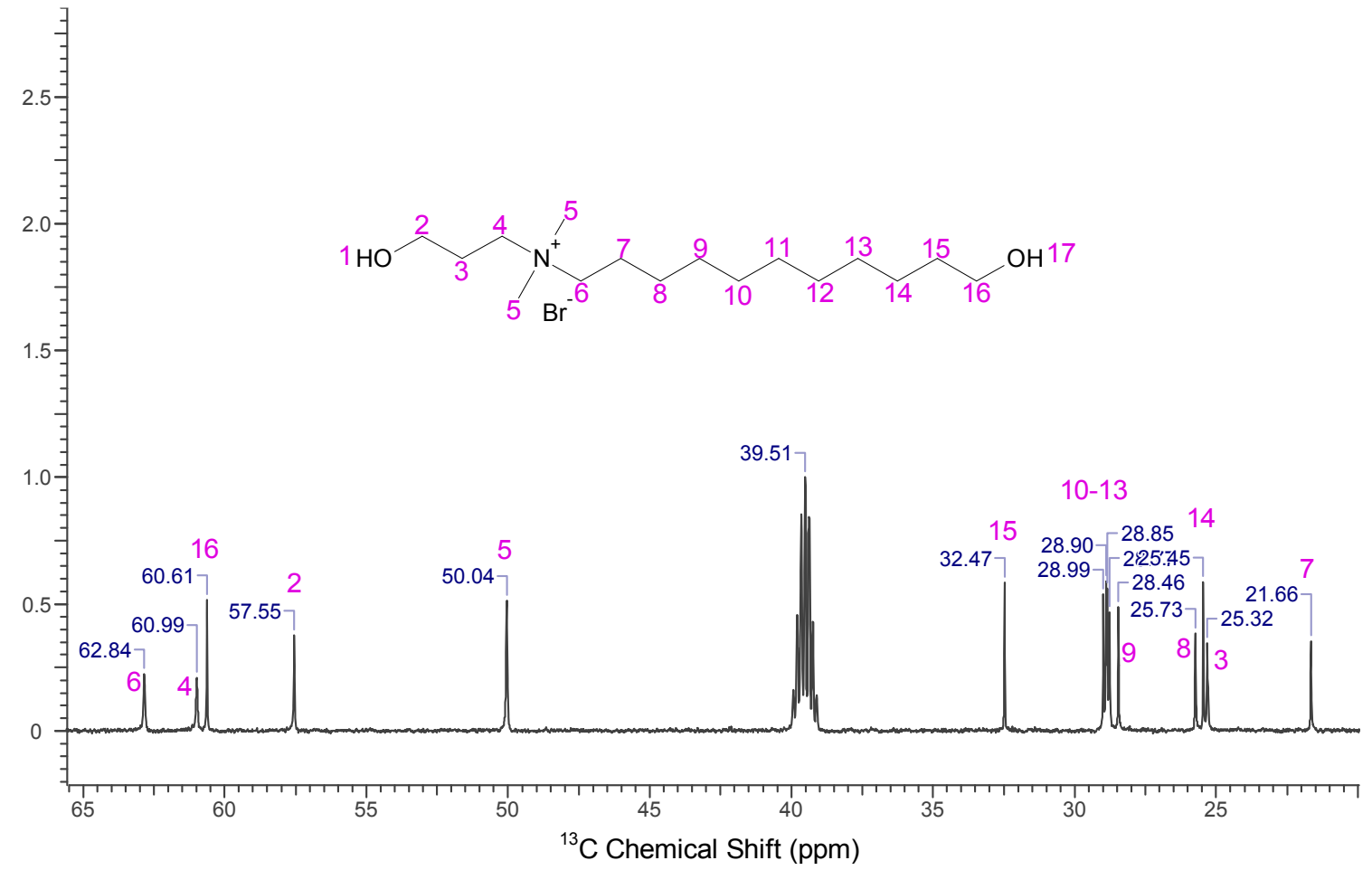

Fig S17 ${ }^{13} \mathrm{C}$ NMR spectrum of HHPdMUABr (6) in DMSO_d $\mathrm{d}_{6}$. 


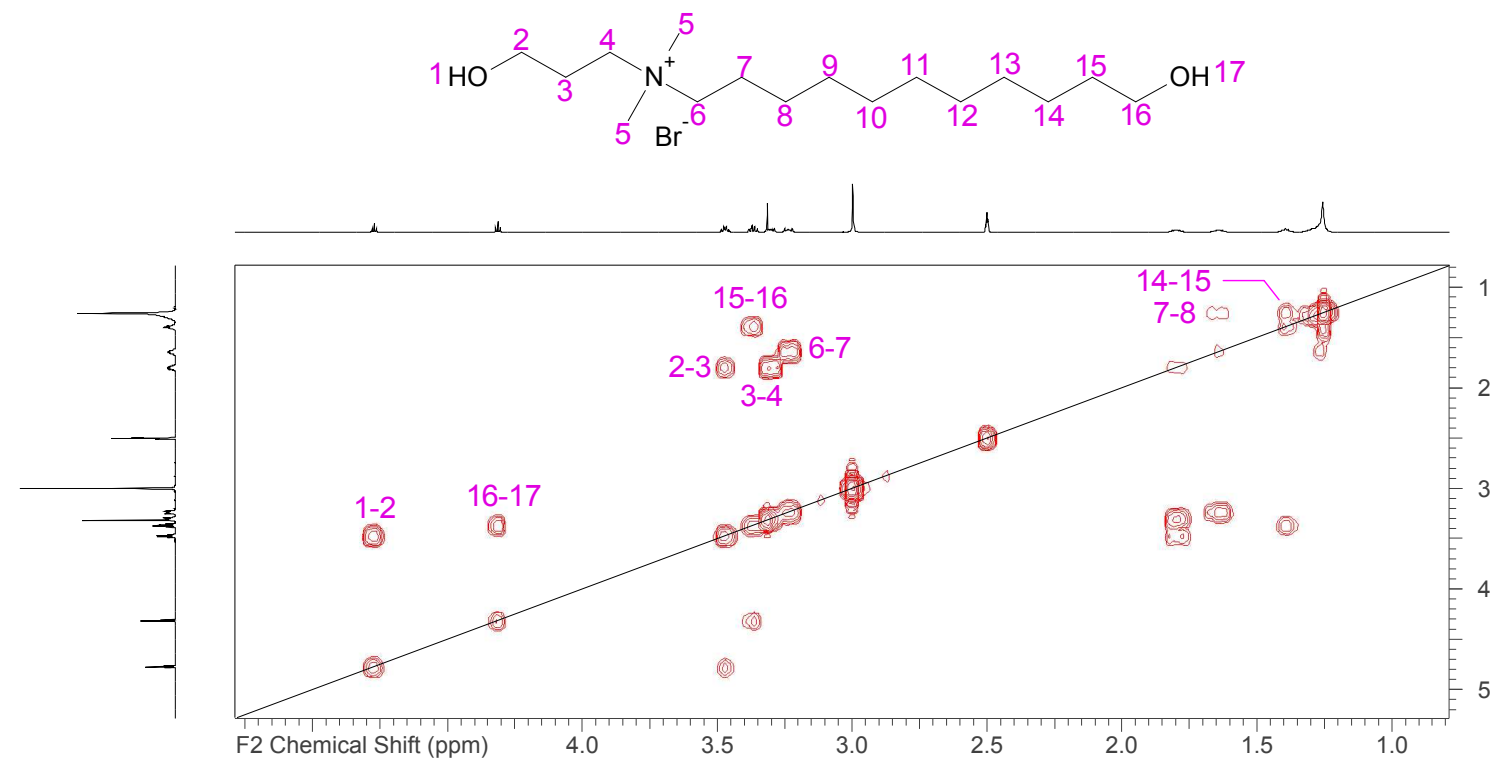

Fig S18 gCOSY NMR spectrum of HHPdMUABr (6) in DMSO_d $d_{6}$. 


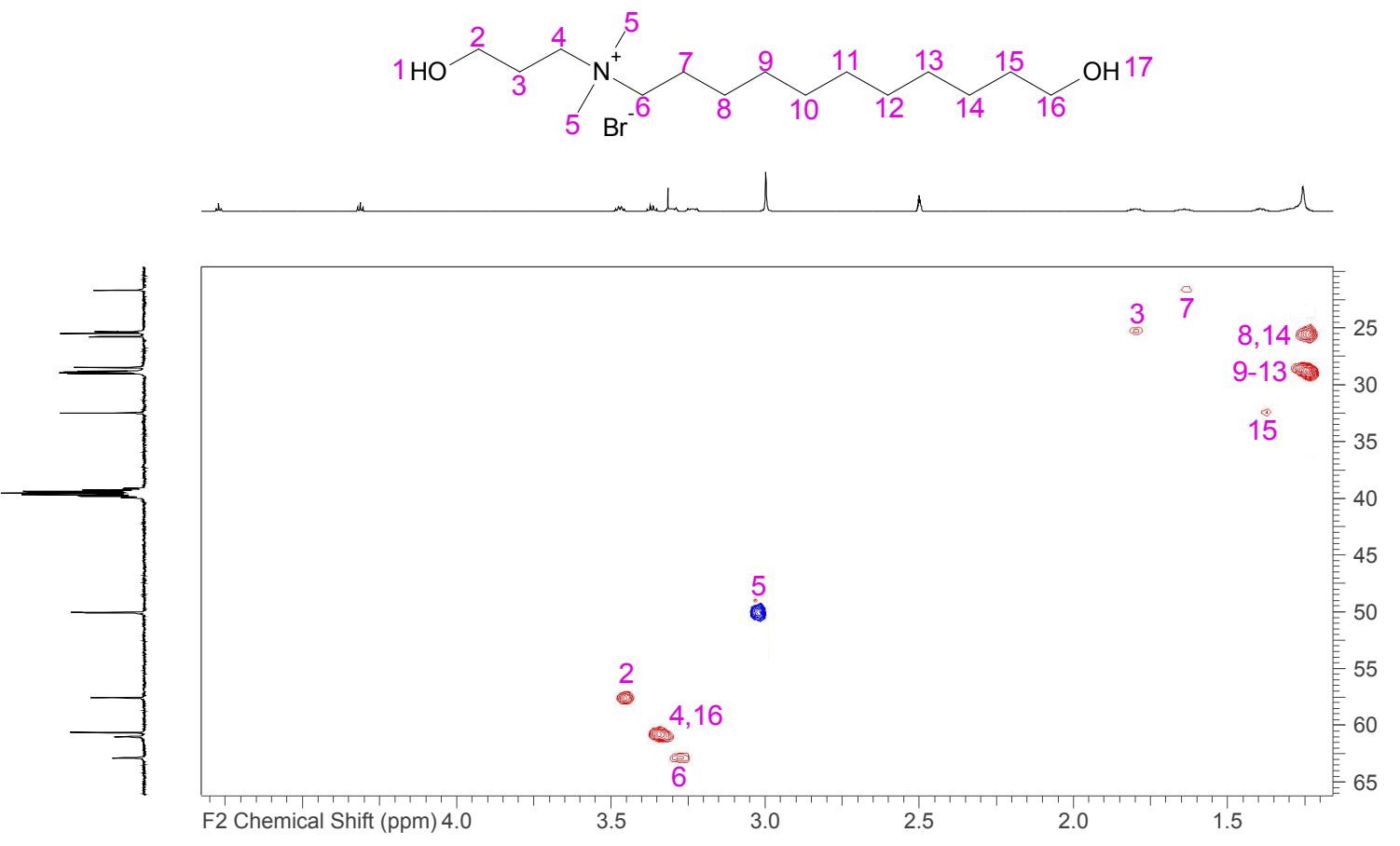

Fig S19 gHSQCAD NMR spectrum of HHPdMUABr (6) in DMSO_d $d_{6}$. 


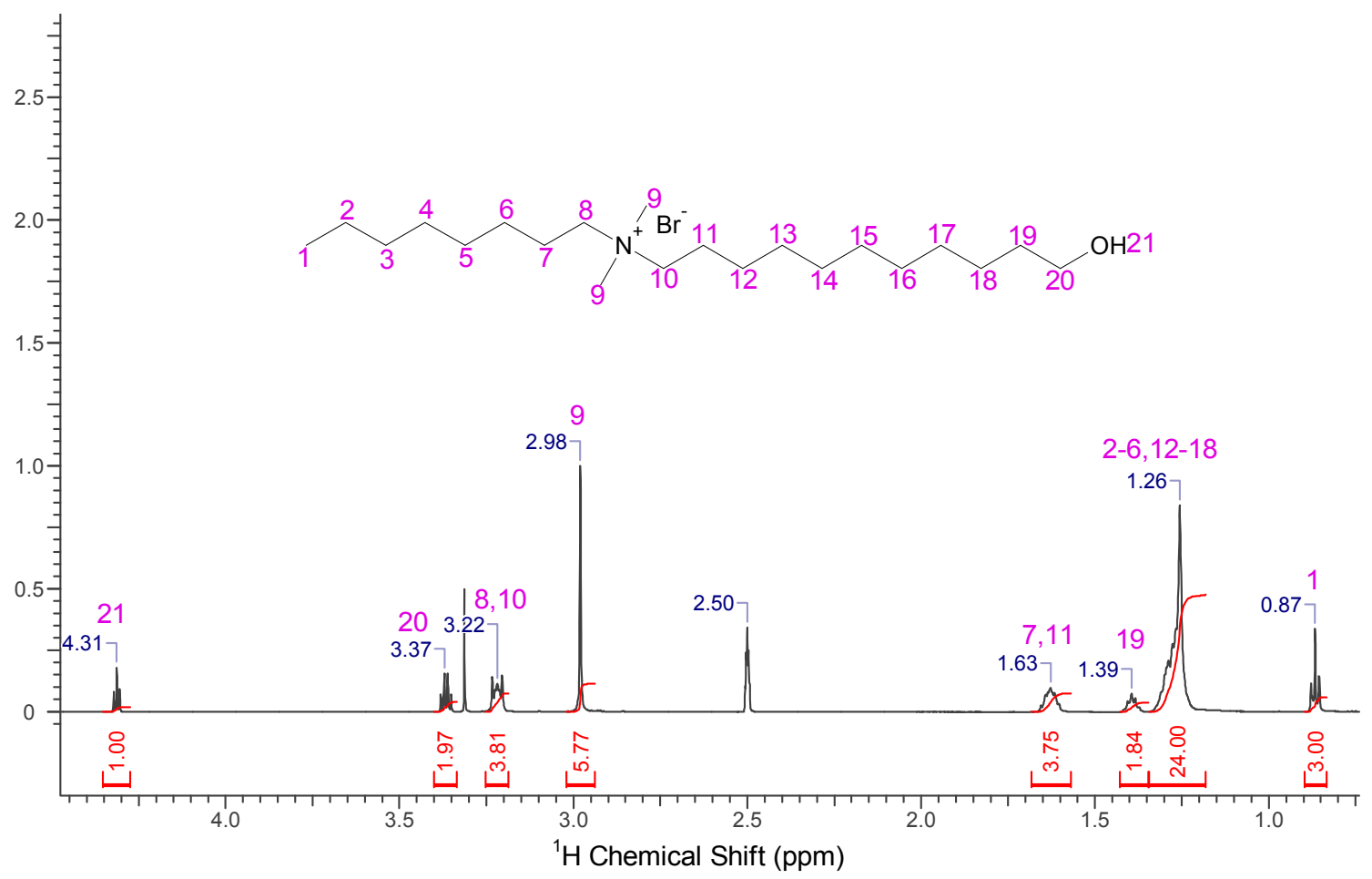

Fig S20 ${ }^{1} \mathrm{H}$ NMR spectrum of HUdMOABr (7) in DMSO_d $\mathrm{d}_{6}$. 


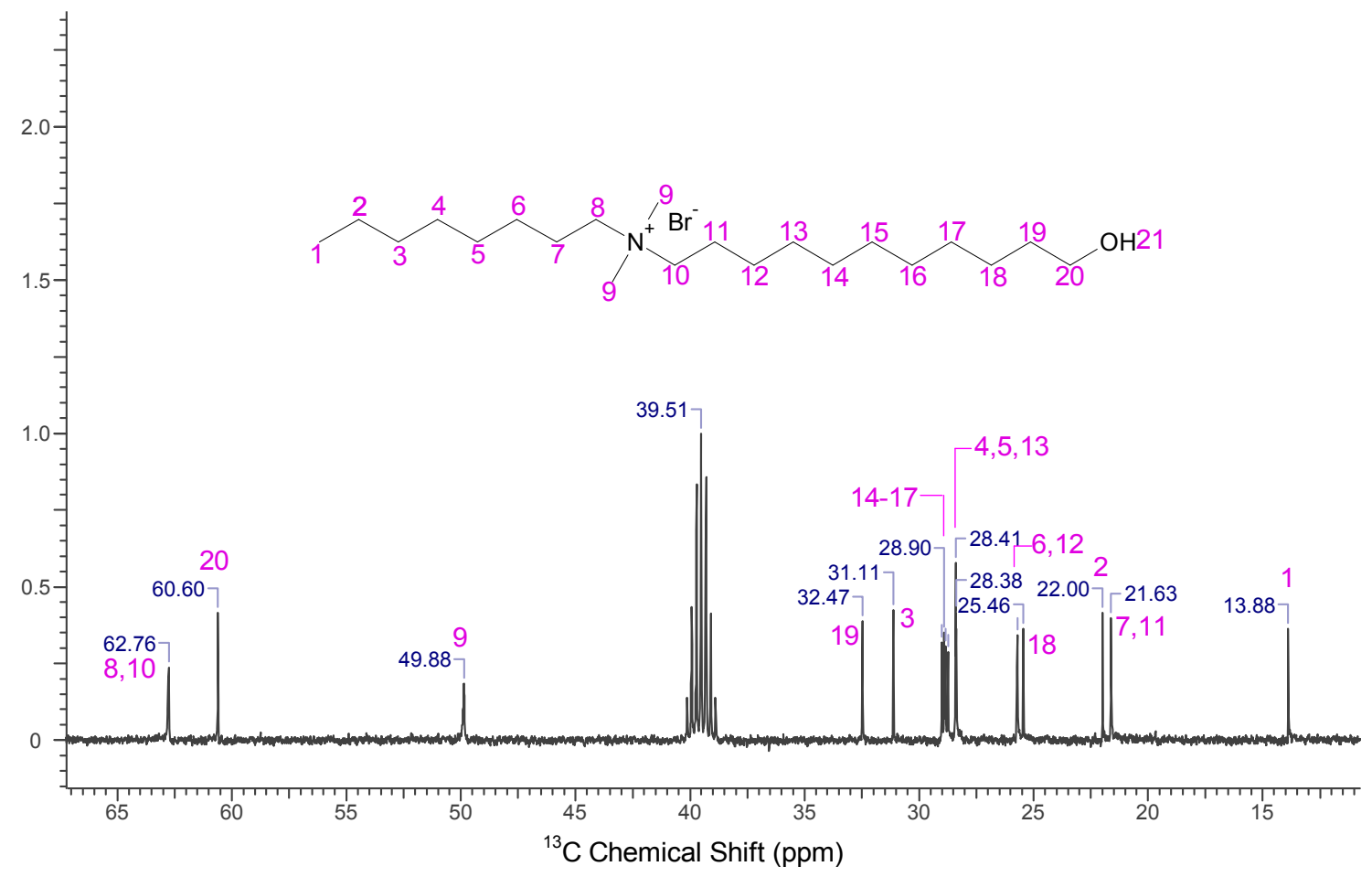

Fig S21 ${ }^{13}$ C NMR spectrum of HUdMOABr (7) in DMSO_d $d_{6}$. 


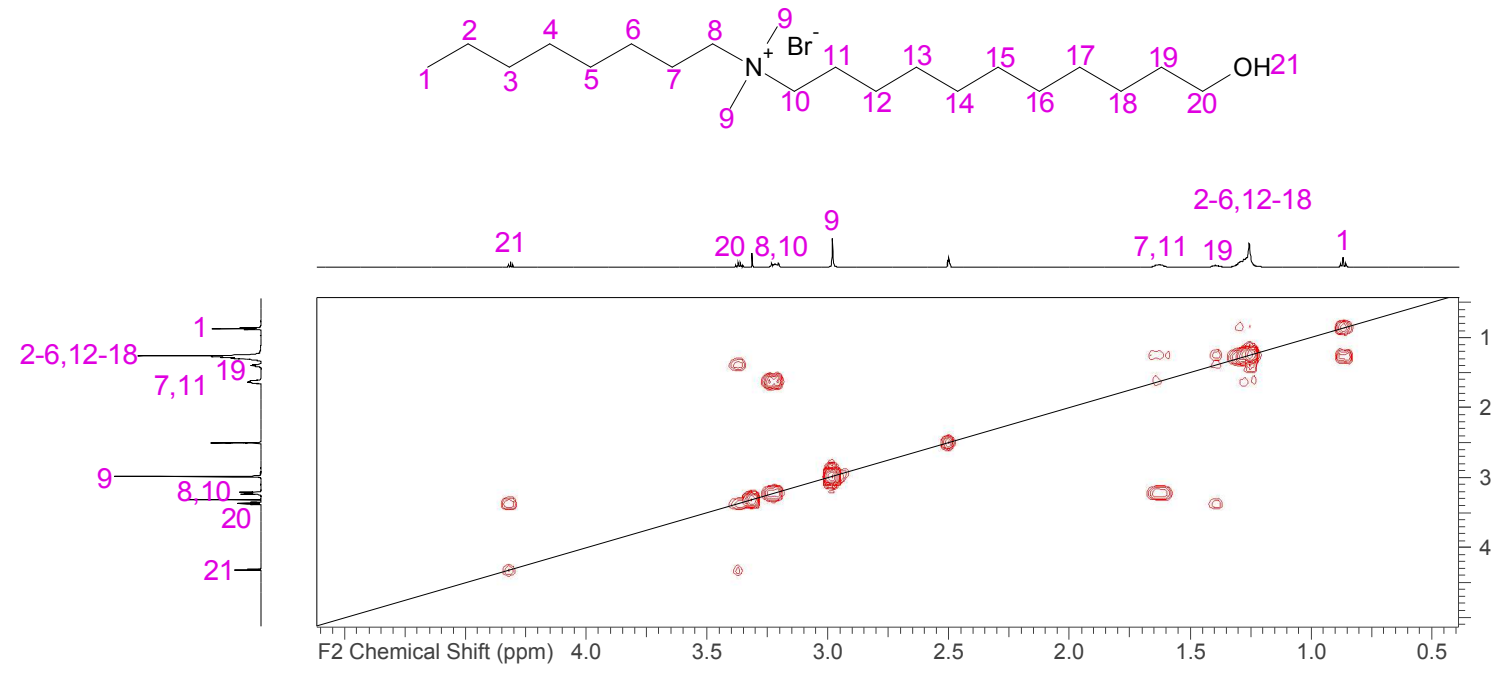

Fig S22 gCOSY NMR spectrum of HUdMOABr (7) in DMSO_d $d_{6}$. 


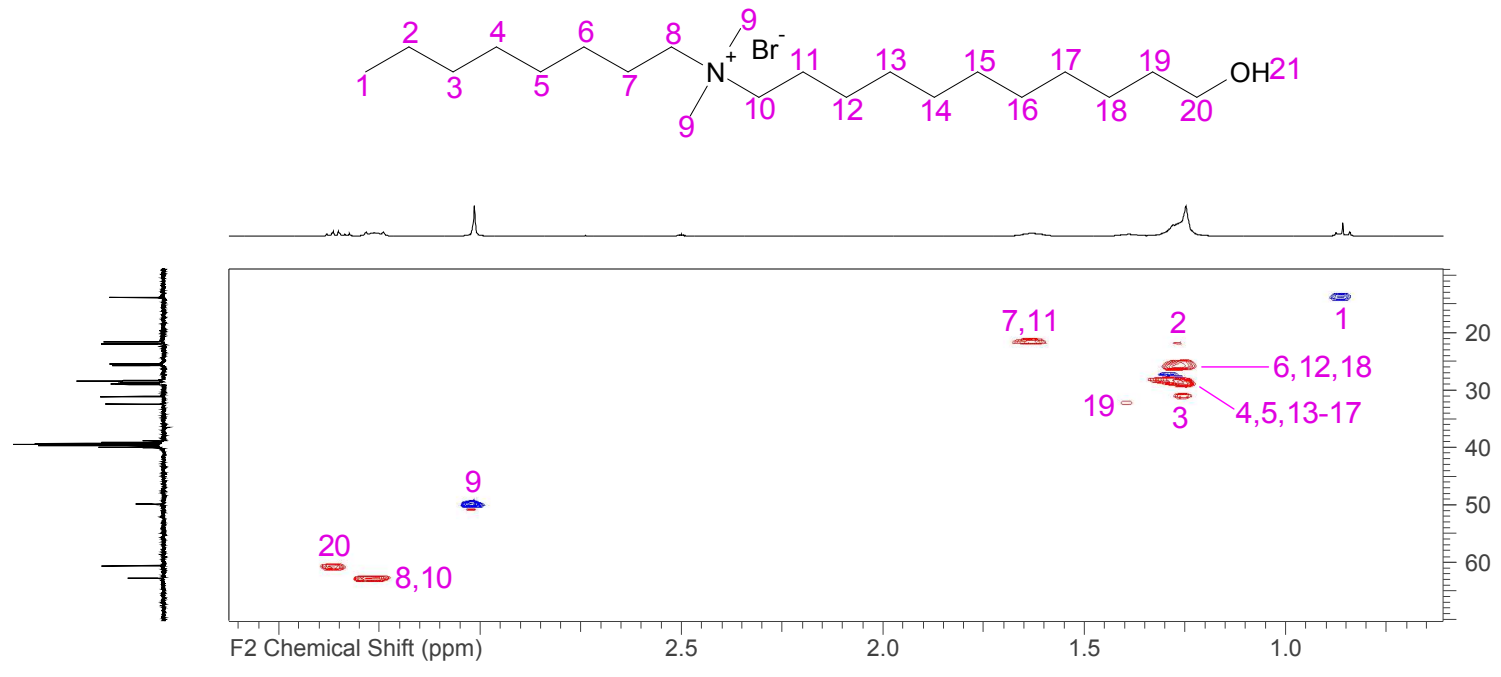

Fig S23 gHSQCAD NMR spectrum of HUdMOABr (7) in DMSO_d $\mathrm{d}_{6}$. 


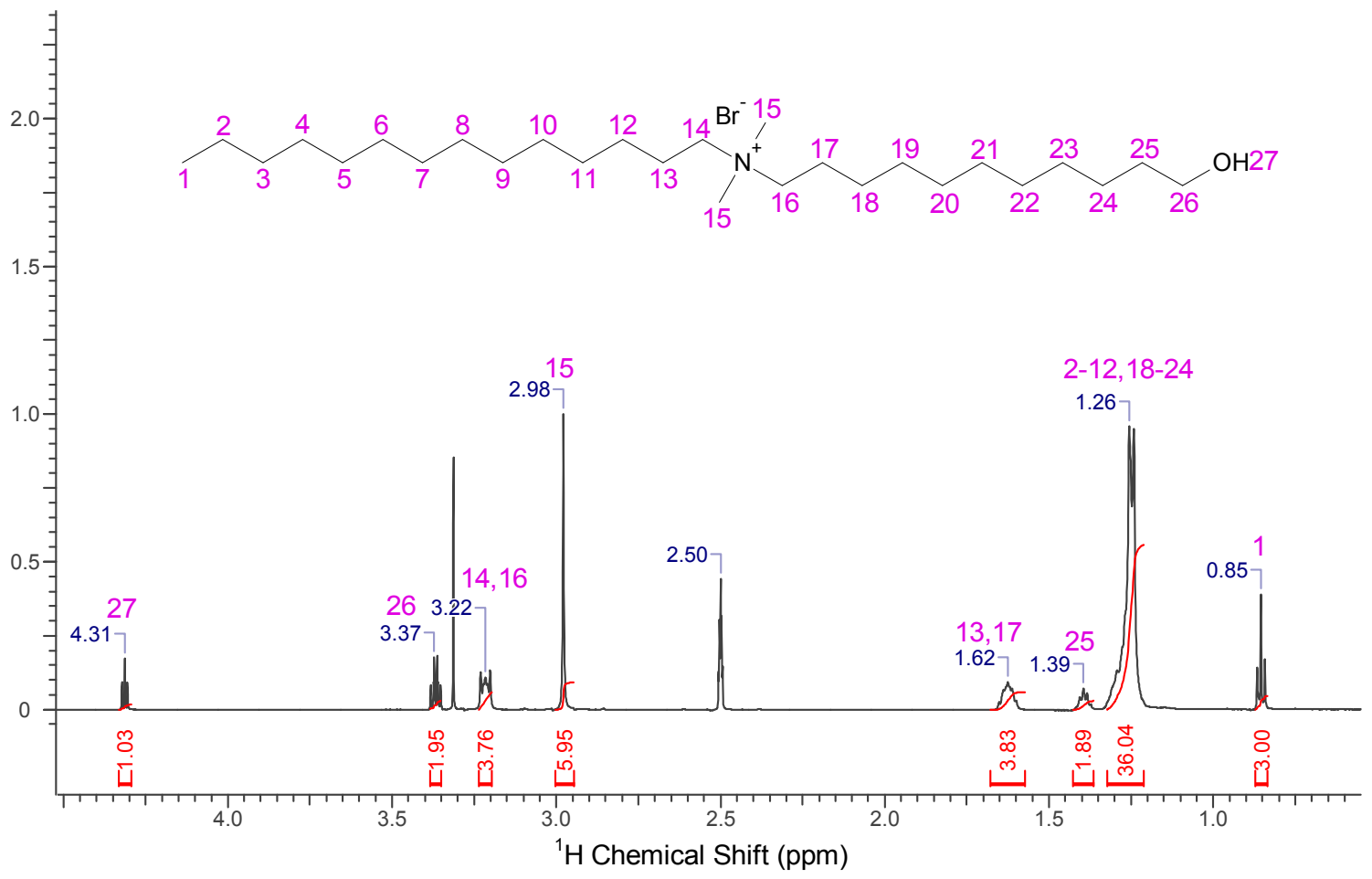

Fig S24 ${ }^{1} H$ NMR spectrum of HUdMTABr (8) in DMSO_ $d_{6}$. 




Fig S25 ${ }^{13}$ C NMR spectrum of HUdMTABr (8) in DMSO_d $d_{6}$. 

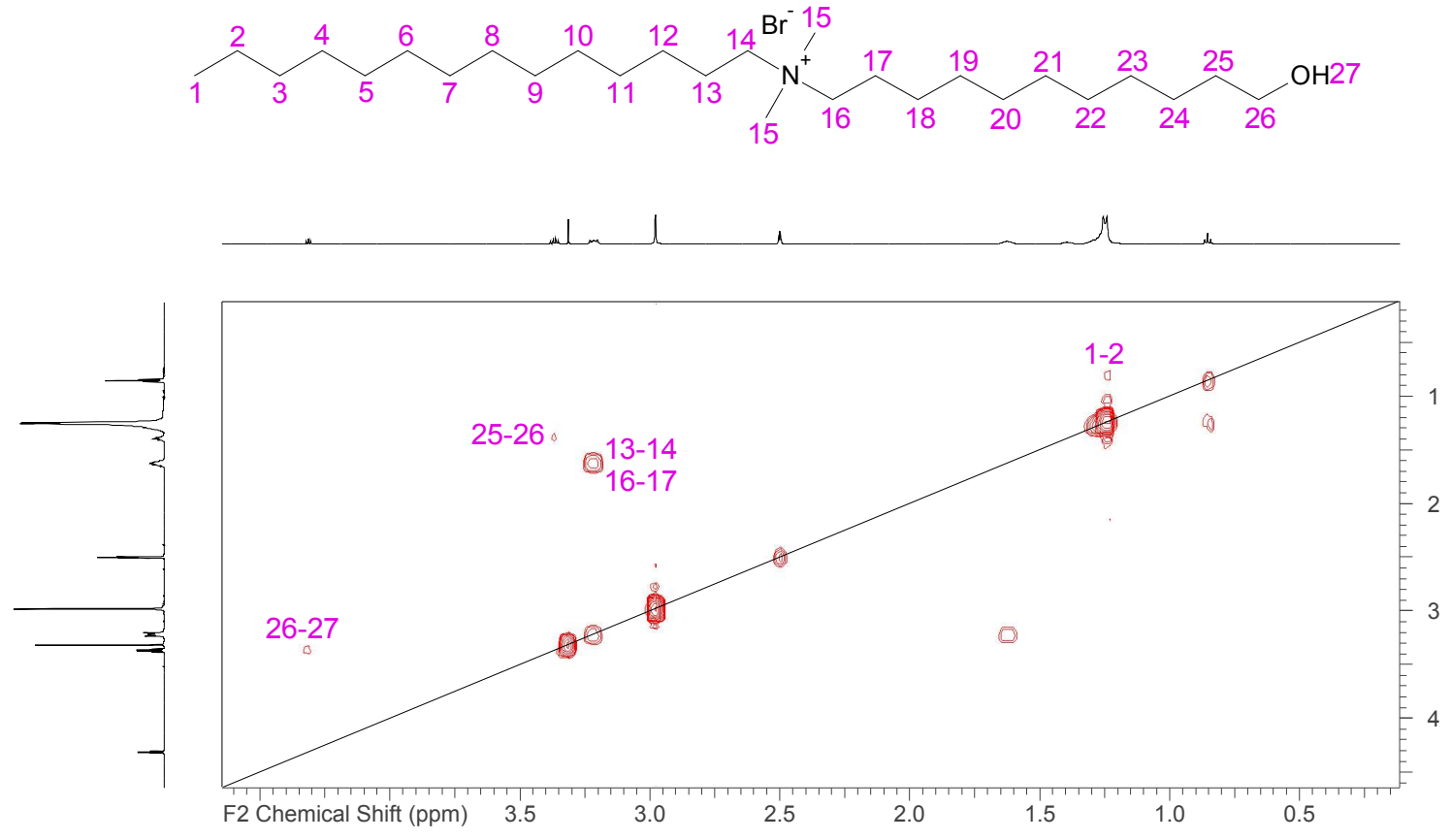

Fig S26 gCOSY NMR spectrum of HUdMTABr (8) in DMSO_d 6 . 


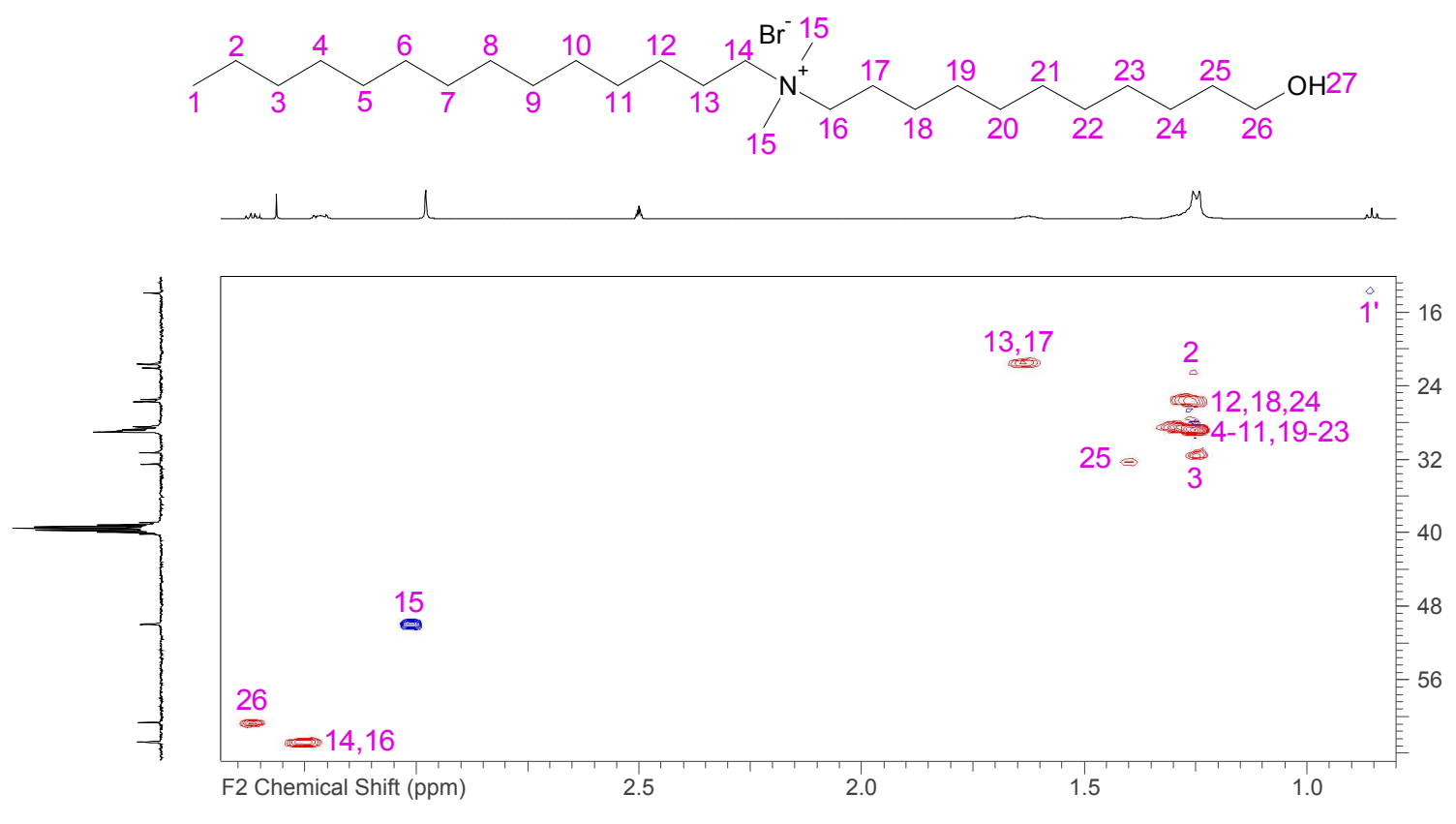

Fig S27 gHSQCAD NMR spectrum of HUdMTABr (8) in DMSO_d $d_{6}$. 


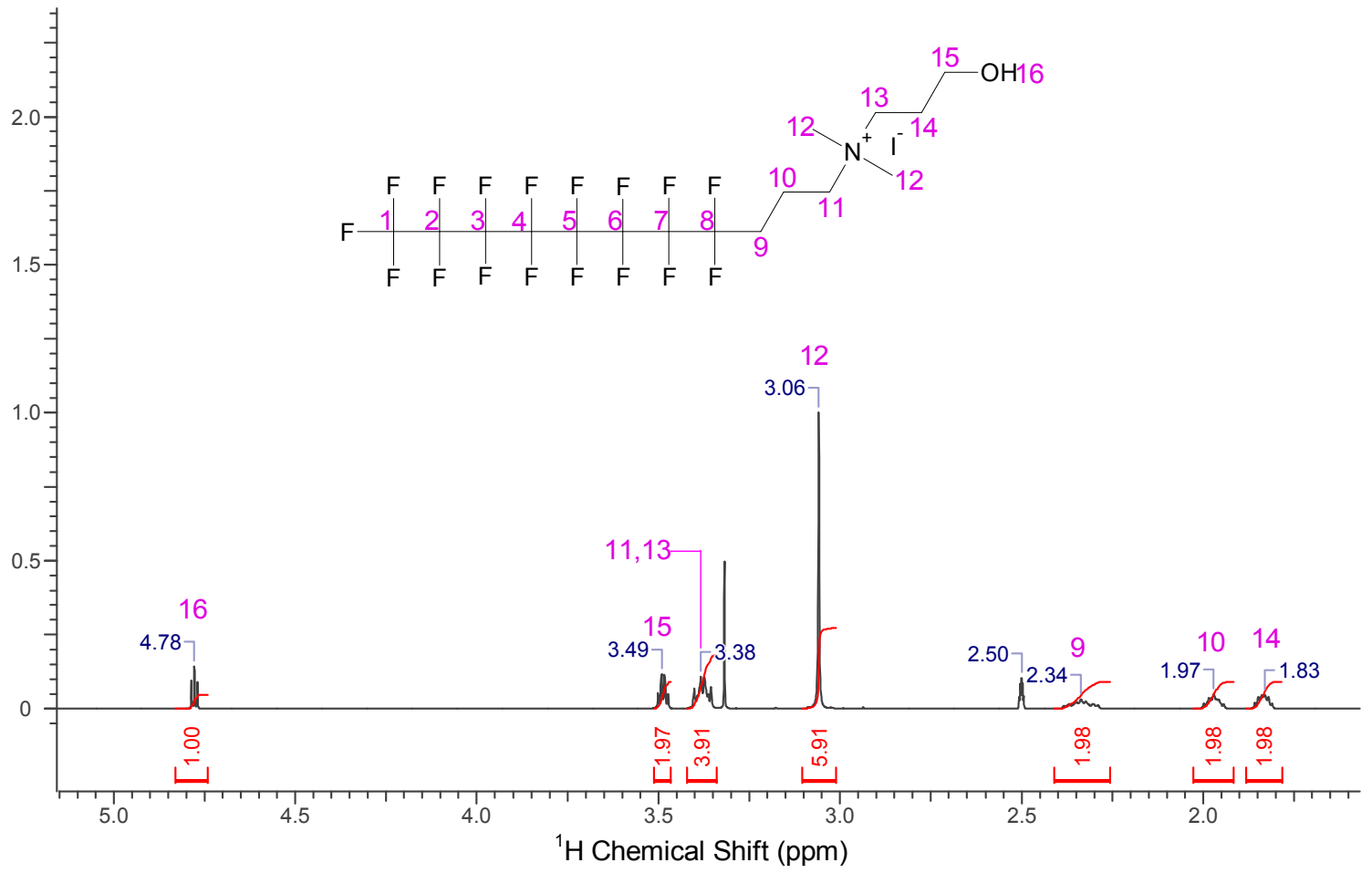

Fig S28 ${ }^{1} \mathrm{H}$ NMR spectrum of $\mathrm{F}_{17} \mathrm{HPdMUAI}(9)$ in DMSO_d $\mathrm{d}_{6}$. 



Fig S29 ${ }^{13} \mathrm{C}$ NMR spectrum of $\mathrm{F}_{17} \mathrm{HPdMUAl}(9)$ in DMSO_d $\mathrm{d}_{6}$. 


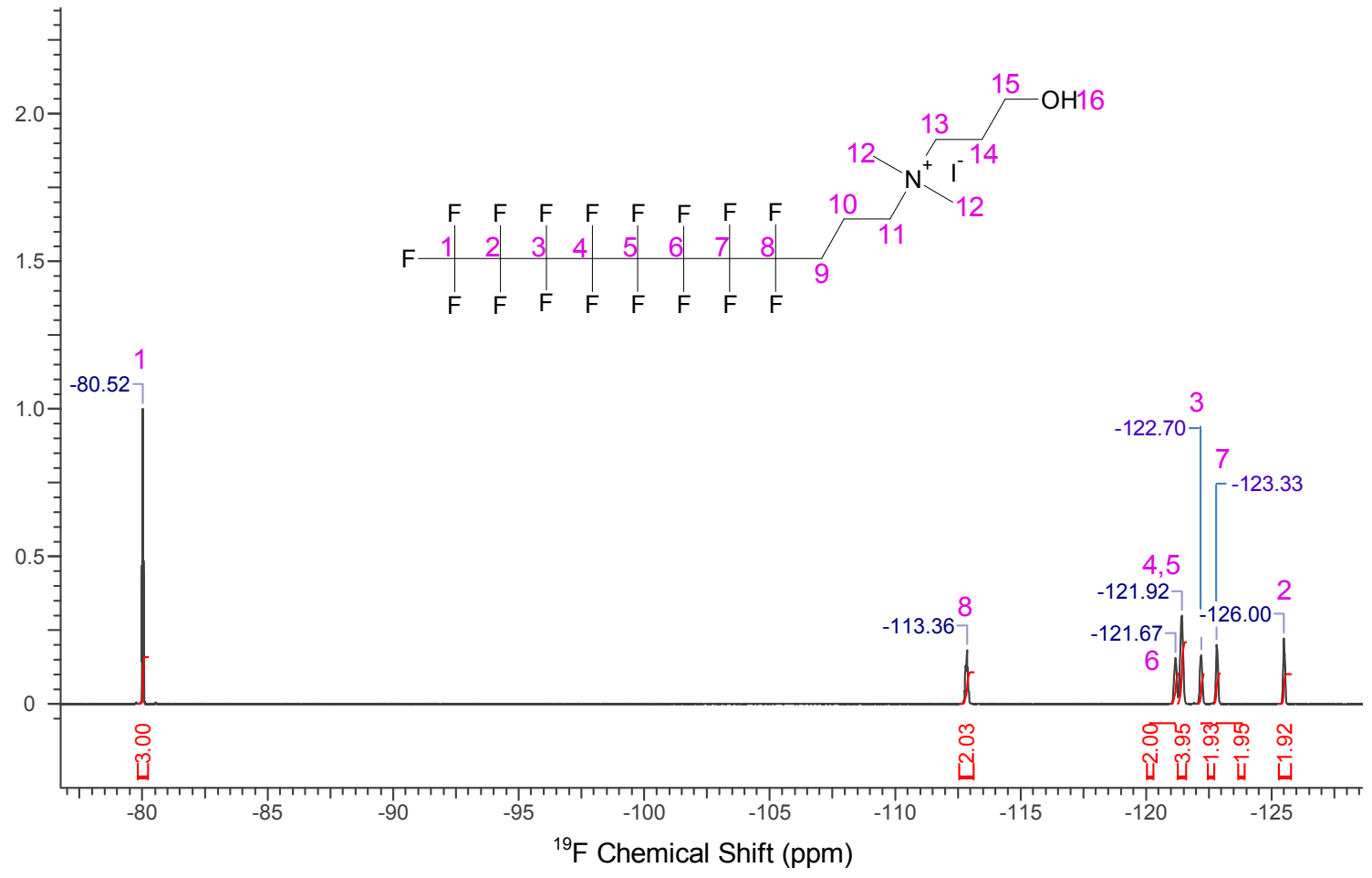

Fig S30 ${ }^{19} \mathrm{~F}$ NMR spectrum of $\mathrm{F}_{17} \mathrm{HPdMUAI}(\mathbf{9})$ in DMSO_d $\mathrm{d}_{6}$. 

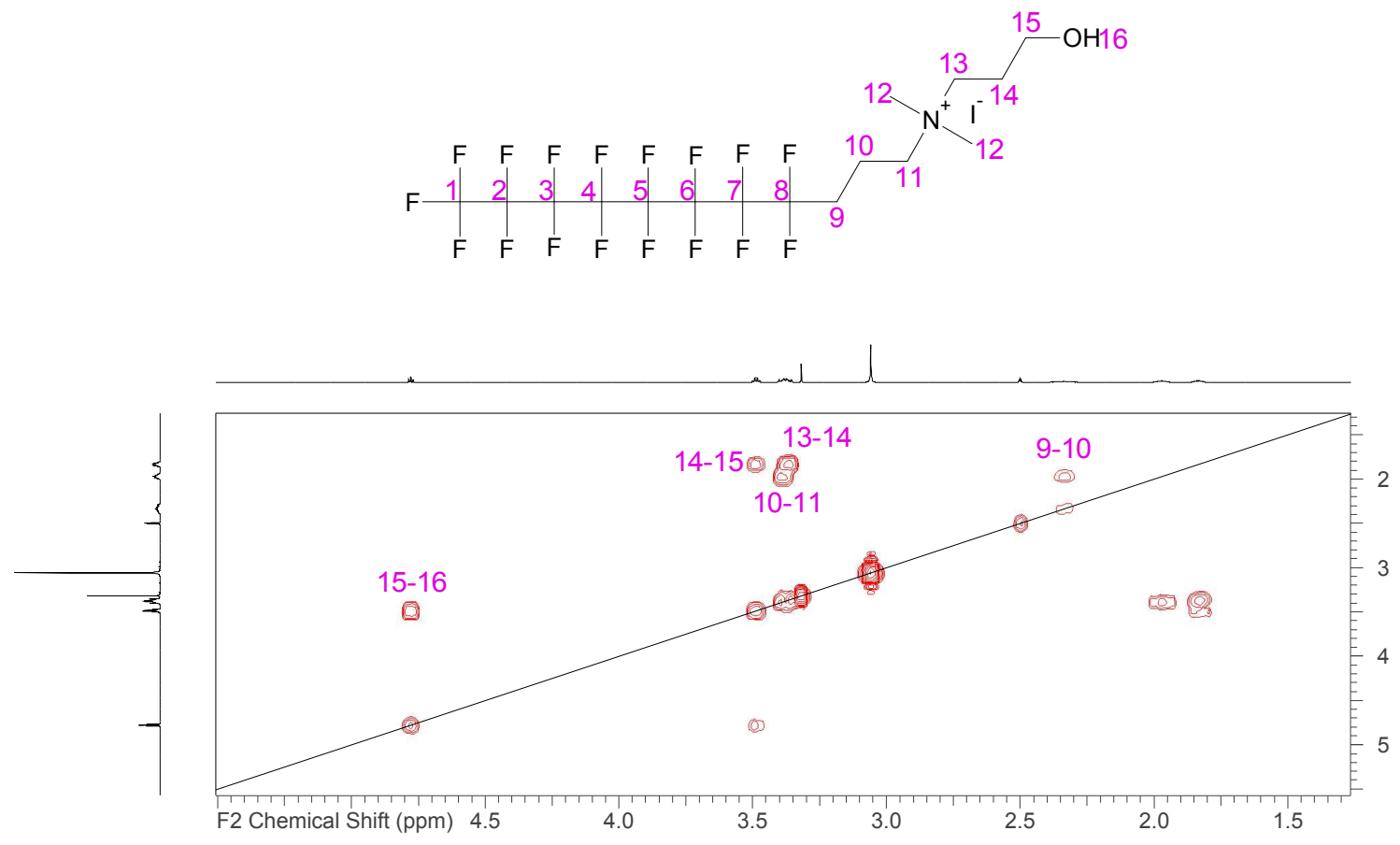

Fig S31 gCOSY NMR spectrum of $F_{17}$ HPdMUAl (9) in DMSO_ $d_{6}$. 